\title{
Effect of particle size on direct compaction of urea fertilizer
}

\begin{abstract}
The effect of particle size on compaction properties and characteristics of urea tablets manufactured from available urea granules (TG tablets) and ground urea powders (TP tablets) was investigated. The compaction properties, namely, plastic work, elastic work, friction work, and maximum ejection pressure were analyzed from the force-displacement profile of the compaction process. Five applied pressures ranging between $37.67 \mathrm{MPa}$ and $188.35 \mathrm{MPa}$ were used to compact the materials using a universal testing machine. Characteristics of the tablets tested were mechanical strength and the release of ammonium ion through dissolution test. The results demonstrated that TG tablets underwent high plastic work and elastic work but low friction work compared to the TP tablets. TG tablets released lower amount of ammonium ion compared to the TP tablets at almost all applied pressures, except at 75.34 $\mathrm{MPa}$. This study provides a valuable data for evaluating the behavior of urea in the form of granules and powders during the compaction process as well as the suitability in choosing the form of raw material for the production of urea tablets.
\end{abstract}

Keyword: Ammonium ion release; Compaction properties; Tensile strength; Universal testing machine; Urea 